\title{
PENGARUH MODEL PEMBELAJARAN DISCOVERY LEARNING TERHADAP HASIL BELAJAR SISWA PADA MATERI POKOK SUHU DAN KALOR
}

\author{
MarizaFitri dan Derlina \\ Jurusan Fisika FMIPA Universitas Negeri Medan \\ Marizafitri85@yahoo.com
}

\begin{abstract}
ABSTRAK
Penelitian ini bertujuan untuk mengetahui apakah ada pengaruh model Discovery Learning terhadap hasil belajar siswa pada materi pokok suhu dan kalor di kelas X Semester II SMA Cerdas Murni Tembung T.P. 2013/2014.Jenis penelitian ini adalah quasi eksperimen. Populasi dalam penelitian ini adalah seluruh siswa kelas X Semester ganjil SMA Cerdas Murni yang terdiri dari tiga kelas. Sampel penelitian ini diambil dua kelas yaitu X-2 (sebagai kelas eksperimen) dan kelas X-3 (sebagai kelas control) yang masing-masing berjumlah 30 siswa yang di tentukan denganteknik Claster Random Sampling. Kemudian diberikan perlakuan yang berbeda, kelas eksperimen dengan model pembelajaran Discovery Learning dan kelas kontrol dengan pembelajaran konvensional. Data yang digunakan dalam penelitian ini yaitu tes essay yang telah divalidkan oleh validator.Dari hasil penelitian diperoleh nilai rata-rata pretes kelas eksperimen dan nilai rata-rata kelas kontrol. Setelah pembelajaran selesai diberikan postes kepada kelas eksperimen dan kelas kontrol. Dari hasil uji t diperoleh $t_{\text {hitung }}>t_{\text {tabel }}$, maka $H_{a}$ diterima, dengan menunjukkan bahwa hasil belajar siswa pada materi pokok suhu dan kalor dengan menerapkan model pembelajaran Discovery Learning lebih baik dari pada pembelajaran konvensional di kelas X Semester II SMA Cerdas Murni T.P. 2013/2014.
\end{abstract}

Kata Kunci : Model Pembelajaran Discovery Learning, Konvensional, HasilBelajar.

\section{PENDAHULUAN}

Kemajuan

bangsasangat ditentukan oleh

kualitas sumber daya manusia (SDM). Kualitas sumber daya manusia sangat bergantung pada kualitas pendidikan. Pendidikan memegang peranan penting dalam pembangunan bangsa. Berhasilnya pembangunan di bidang pendidikan akan sangat berpengaruh terhadap pembangunan di bidang yang lainnya. Oleh karena itu, pembangunan dalam bidang pendidikan sekarang ini semakin giat dilaksanakan. Berbagai carapun ditempuh untuk memperoleh pendidikan baik pendidikan secara formal maupun pendidikan secara nonformal .

Perkembangan dalam bidang pendidikan berkaitan erat dengan perkembangan ilmu pengetahuan dan teknologi (IPTEK). Pesatnya perkembangan ilmu pengetahuan dan teknologi tidak dapat terlepas dari kemajuan ilmu fisika yang banyak menghasilkan temuan baru dalam bidang sains dan teknologi. Fisika ditempatkan sebagai salah 
satu mata pelajaran yang penting karena salah satu syarat penguasaan ilmu pengetahuan dan teknologi.

Fisika merupakan salah satu cabang sains yang mempelajari fenomena dan gejala alam secara empiris, logis, sistematis dan rasional yang melibatkan proses dan sikap ilmiah. Ketika belajar fisika, siswa akan dikenalkan tentang produk fisika berupa materi, konsep, asas, teori, prinsip, dan hukum-hukum fisika. Siswa juga akan diajarkan untuk bereksperimen di dalam laboratorium atau di luar laboratorium sebagai proses ilmiah untuk memahami berbagai pokok bahasan fisika lestari ( 2014).

Kegiatan pembelajaran fisika lebih menekankan pada pemberian langsung untuk meningkatkan kompetensi agar siswa mampu berpikir kritis dan sistematis dalam memahami konsep fisika, sehingga siswa memperoleh pemahaman yang benar tentang fisika. Pemahaman yang benar akan pelajaran fisika sangat berpengaruh terhadap hasil belajar siswa.

Pembelajaran fisika di sekolah masih bersifat verbal,siswa tampak pasif dan menerima pengetahuan sesuai dengan apa yang diberikan guru, proses belajar mengajar yang dilakukan di sekolah masih berpusat pada guru. Saat guru memberikan kesempatan untuk bertanya atau menjawab siswa hanya diam karena mereka bingung apa yang harus ditanyakan dan dijawab.

Sesuai dengan pengalaman peneliti saat melakukan praktek program pengalaman lapangan Terpadu ( PPLT ) di SMP Negeri 2
Sipispis banyak sekali siswa yang menyatakan bahwa pelajaran fisika merupakan pelajaran yang sulit untuk dipahami dan membosankan. Cenderung dianggap identik dengan rumus yang banyak dan susah untuk diingat, guru lebih sering menggunakan pola mengajar dengan menyajikan meteri dan menyelesaikan soal-soal dengan rumus.Siswa hanya dapat menghitung tetapi tidak dapat mengerti konsep fisika sebenarnya.

Kenyataan tersebut juga dijelaskan berdasarkan observasi yang dilakukan di SMA Cerdas Murni bahwa minat dan motivasi belajar siswa masih tergolong rendahyaitu $<50 \quad$ kususnya Fisika,banyak siswa yang beranggapan bahwa fisika itu sulit sehingga keinginan untuk mengikuti pelajaran fisika cenderung menurun.

Hasil wawancara yang dilakukan kepada guru SMA Cerdas Murni mengatakan bahwa hasil nilai rata-rata fisika siswa pada ujian akhir semester ganjil T.P 2012/2013 adalah 65.Hasil belajar ini masih jauh dari yang diharapkan.Sedangkan untuk ulangan harian fisika hanya 1-5 orang saja yang mampu mencapai nilai di atas KKM (67). Hal ini diduga terjadi karena model pembelajaran yang digunakan kurang bervariasi, pembelajaran fisika lebih dominan menggunakan strategi pembelajaran konvensional dimana guru adalah sebagai pusat pemberi informasi tanpa melibatkan siswa untuk ikut aktif sehingga karakter-karakter diatas tidak dimiliki oleh siswa.Dalam proses pembelajaran, guru harus melaksanakan model pembelajajaran yang bervariasi 
agar siswa dapat belajar secara efektif dan efisien serta mengena pada tujuan yang diharapkan.

$\begin{array}{ccc}\text { Salah } & \text { satu } & \text { model } \\ \text { pembelajaran } & \text { yang } & \text { dapat }\end{array}$
meningkatkan hasil belajar siswa melalui penalaran, menemukan sesuatu untuk dirinya dalam memahami struktur ide-ide kunci yaitu dengan menerapkan model pembelajaran Discovery Learning. "Model pembelajaran Discovery Learning lebih unggul dalam meningkatkan hasil belajar dibandingkan pengalamanpengalaman belajar individual atau kompetitif".

Salah satu pembenahan dalam proses pembelajaran fisika yang dapat dilakukan adalah dengan cara mengembangkan model pembelajaran Discovery Learning. Model pembelajaran ini dikembangkan oleh Jerome Bruner(dalam arend2008:48). Discovery Learning merupakan sebuah model pengajaran yang dirancang dengan tujuan untuk membantu siswa mengembangkan kemampuan berfikir dan mengembangkan kemampuan dalam memecahkan masalah kehidupan sehari-hari, yang menekankan pada pentingnya membantu siswa untuk memahami struktur atau ide-ide kunci suatu disiplin ilmu, kebutuhan akan keterlibatan aktif siswa dalam proses belajar, dan keyakinan bahwa pembelajaran sejati terjadi melalui penemuan pribadi. mengembangkan kemampuan dalam memecahkan masalah kehidupan sehari-hari. Model pembelajaran Discovery

Learningdiharapkan dapat meningkatkan hasil belajar siswa.
Persaingan yang positif akan terjadi di kelas dalam rangka pencapaian prestasi belajar yang optimal. Pembelajaran Discovery Learningdiharapkan dapat membantu siswa untuk memahami struktur atau ide-ide kunci dan penemuan pribadi(Kemendikbud, 2013).

Dari uraian tersebut diatas, timbul sebuah pertanyaan apakah dengan menggunakan model pembelajaran Discivery Learning dapat meningkatkan hasil belajar siswa pada pokok bahasan Suhu dan Kalor di SMA? Untuk menjawab pertanyaan diatas maka dibuatlah suatu penelitian yang berjudul "Pengaruh Model Pembelajaran Discovery Learning Terhadap Hasil Belajar siswa Pada Pokok Bahasan Suhu dan Kalor kelas X SMA Cerdas Murni Medan T.P. 2013/1014".

\section{METODE PENELITIAN}

Penelitian dilaksanakan di SMA Cerdas Murni TembungdenganPopulasi seluruh siswa kelas X SMA Cerdas Murni sebanyak 3 kelas.Pengambilan sampel dilakukan secara cluster random sampling. Dari 3 kelas hanya 2 kelas yang dijadikan sampel penelitian. Satu kelas sebagai kelas eksperimen yaitu kelas yang menggunakan model pembelajaran Discovery Learning dan kelas kontrol yaitu kelas yang menggunakan model pembelajaran konvensional.Variabel dalam penelitian ini terbagi atas dua jenis yaitu variabel bebas dan variabel terikat. Dalam penelitian ini adalah dapat dijelaskan bahwa :

a. Sebagai variabel bebas adalah model pembelajaran Discovery Learning 
b. Sebagai variabel terikat adalah hasil belajar siswa pada materi pokok Suhu dan Kalor

Penelitian ini termasuk jenis penelitian quasi eksperiment, dengan desain two group pretestpostest designseperti yangditunjukkanpadatabel 1 dibawahini :

Tabel 1. Desain Penelitian tipe Two GroupPretest Postest

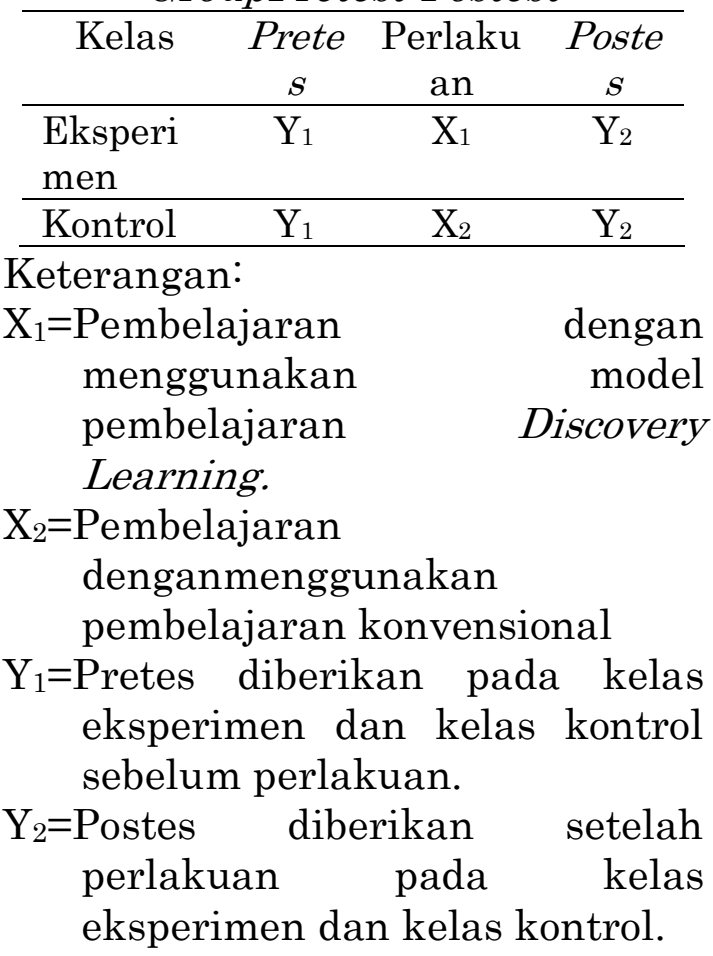

Instrument tes hasil belajar yang digunakan berjumlah lima belas soal dalam bentuk essay dan diberikan sebanyak 2 kali yaitu pretes dan postes.

Uji hipotesis yang digunakandenganmenggunakanuji $\mathrm{t}$ dengan membandingkan rata-rata skor hasil belajar yang dicapai baik kelas eksperimen maupun kelas kontrol. Data yang diperoleh ditabulasikan kemudian dicari rata-ratanya. Sebelum dilakukan penganalisisan data, terlebih dahulu ditentukan skor masingmasing kelompok sampel lalu dilakukan pengolahan data dengan langkah-langkah sebagai berikut: a) Menghitung nilai rata-rata dan simpangan baku

b) Uji normalitas

c) Uji homogenitas

d) Ujikesamaan rata-rata pretes

Uji $t$ digunakan untuk mengetahui kesamaan kemampuan awal siswa pada kedua kelompok sampel. Hipotesis yang diuji berbentuk:

$\mathrm{H}_{\mathrm{o}}: \mu_{1}=\mu_{2}$ : kelas eksperimen dan kelas kontrol mempunyai kemampuan awal yang sama.

$\mathrm{H}_{\mathrm{a}}: \mu_{1} \neq \mu_{2}:$ kelas eksperimen dan kelas kontrol mempunyai kemampuan awal yang berbeda.

e) Pengujian hipotesis

Uji t juga digunakan untuk mengetahui perbedaan dari suatu perlakuan yaitu model pembelajaranDiscovery

Learningterhadap hasil belajar siswa. Hipotesis yang diuji berbentuk:

$$
\begin{aligned}
& \mathrm{Ho}: \square_{1} \leq \square_{2} \\
& \mathrm{Ha}: \square_{1}>\square_{2}
\end{aligned}
$$

Keterangan :

$\left.\sigma_{1} \leq\right]_{2}$ : Tidak ada perbedaan hasil belajar siswa akibat pengaruh model pembelajaran model pembelajaran Discovery

Learning dengan pembelajaran konvensional.

四 $>$ 示 : Ada perbedaan hasil belajar siswa akibat pengaruh model pembelajaran Discovery Learnig dengan pembelajaran konvensional.

\section{HASIL PENELITIAN DAN PEMBAHASAN \\ Hasil Penelitian}

Pada awal pertemuan kedua kelas diberikan pretes untuk melihat tingkat kemampuan awal 
siswa dan untuk mengetahui apakah tingkat penguasaan siswa terhadap pelajaran tersebut pada awal penelitian tidak berbeda secara signifikan.rata-rata 34,6 dan simpangan baku 11,11. Dan kelas kontrol diperoleh nilai rata-rata 33,2 dan simpangan baku 12,33.

Setelah memperoleh data hasil pretes siswa dari kelas eksperimen dan kelas kontrol,

\begin{tabular}{|c|c|c|c|c|}
\hline No & Kelas & $\begin{array}{c}\text { \%Pert } \\
\text { I }\end{array}$ & $\begin{array}{c}\text { \%Pert } \\
\text { II }\end{array}$ & $\begin{array}{c}\text { \%Pert } \\
\text { III }\end{array}$ \\
\hline 1 & $\begin{array}{c}\text { Kelas } \\
\text { Eksperi } \\
\text { men }\end{array}$ & 65,1 & 68,0 & 72,6 \\
\hline
\end{tabular}

maka dilakukan pengujian analisis data dengan menggunakan uji kesamaan rata-rata pretes dimana syaratnya data harus berdistribusi normal dan homogen.Hasil uji normalitas, homogenitas dan kesamaan rata-rata pretes ditunjukkan pada Tabel 2 .

Tabel 2. Hasil Uji Normalitas, Homogenitas dan Kesamaan Ratarata Pretes.

Berdasarkan Tabel 2 data pretes kedua kelas normal, homogen dan tidak ada perbedaan secara signifikan, maka pada kedua kelas sampel diberikan perlakuan yang berbeda, pada kelas eksperimen diberikan perlakuan dengan menerapkan model pembelajaran Discovery Learningsedangkan pada kelas kontrol diberikan perlakuan dengan menerapkan pembelajaran konvensional.Setelah diberikan perlakuan yang berbeda, kedua kelas diberikan postes untuk melihat adanya perbedaan akibat penerapan model pembelajaran yang berbeda.
Penilaian sikap harus menjadi bagian dari hasi belajar dan harus tampak dalamproses belajar yang dicapai oleh siswa yang dinilai hasil-hasilnya. Dalam penelitian ini yang menjadi aspekaspek dalam penilaian sikap adalah berdiskusi dengan teman kelompok, bertanggung jawab, mendengarkan dan menanggapi, bertanya sesame teman kelompok, bertanmya dengan peneliti. Hasil penilaian sikap siswa pada kelas kontrol dapat ditunjukkanpada Tabel 3 :

Tabel 3. Penilaian Keterampilan Siswa pada Pertemuan I, II dan III

BerdasarkanTabel 3 dapat dilihat bahwa perkembangan keterampilan siswa di kelas eksperimen selama menerima pembelajaran dengan

\begin{tabular}{|l|l|l|l|l|l|l|l|}
\hline kelas & $\begin{array}{l}\text { Rata } \\
- \\
\text { rata }\end{array}$ & $\begin{array}{l}\text { Lhit } \\
\text { ung }\end{array}$ & $\begin{array}{l}\mathbf{L}_{\text {ta }} \\
\text { bel }\end{array}$ & $\begin{array}{l}\mathbf{F}_{\text {hit }} \\
\text { ung }\end{array}$ & $\mathbf{F}_{\text {tabel }}$ & $\mathbf{t}_{\text {hit }}$ & $\mathbf{t}_{\text {tab }}$ \\
\hline $\begin{array}{l}\text { Eksp } \\
\text { erime } \\
\text { n }\end{array}$ & 34,6 & $\begin{array}{l}0,1 \\
49\end{array}$ & $\begin{array}{l}0,1 \\
61\end{array}$ & $\begin{array}{l}1,0 \\
2\end{array}$ & 2,42 & $\begin{array}{l}0,4 \\
5\end{array}$ & $\begin{array}{l}1,9 \\
8\end{array}$ \\
\cline { 1 - 2 } $\begin{array}{l}\text { Kontr } \\
\text { ol }\end{array}$ & 33,2 & $\begin{array}{l}0,1 \\
12\end{array}$ & & & Homogen & $\begin{array}{l}\text { Kemam } \\
\text { puan } \\
\text { awal } \\
\text { siswa } \\
\text { sama }\end{array}$ \\
\hline \multicolumn{2}{|l|}{ Kesimpulan } & \multicolumn{2}{|l|}{ Normal } & & & &
\end{tabular}

menggunakan model pembelajaran Discovery Learninglebih tinggi.

\section{Pembahasan}

Penelitian yang dilakukan di SMA Cerdas Murni menggunakan dua model pembelajaran yang berbeda kepada kedua kelompok siswa, satu kelas dengan menggunakan model pembelajaran Discovery Learning dan satu lagi 
sebagai kelas pengendali yaitu dengan menggunakan model pembelajaran konvensional (kelas kontrol).

Pada awal pembelajaran siswa diberikan prites untuk mengetahui kemampuan awal siswa dengan rata-rata pre-tes siswa kelas kontrol 33,2 dan nilai rata-rata pre-tes kelas eksperimen 34,6. Pada akhir pembelajaran siswa diberikan pos-tes untuk mengetahui bagaimana hasil belajar kedua kelompok siswa setelah diberikan perlakuan. Hasil penelitian diperoleh rata-rata postes siswa yang diajarkan dengan model pembelajaran Discovery Learning (kelas eksperimen) adalah 75,83 sedangkan untuk kelas kontrol yang menggunakan model pembelajaran konvensional 70,3. Berdasarkan hasil ini dapat dilihat bahwa ada perbedaan yang signifikan hasil belajar (pos-tes) kedua kelompok siswa. Dengan menggunakan model pembelajaran Discovery Learning hasil belajar siswa lebih baik, karena siswa dituntuk untuk lebih aktif, pada saat proses belajar mengajar siswa melakukan diskusi kelompok dan berusaha untuk menemukan pemecahan masalah yang diberikan oleh guru, serta untuk memahami struktur atau ide-ide kunci.

Model pembelajaran Discovery diteliti sebelumnya oleh Lestari (2014) pada Materi Pokok Suhu dan Kalor Terhadap Hasil Belajar Siswa di MAN 1 Sukomoro. Dengan menggunakan Model Pembelajaran Discovery,Hasil belajar kelas eksperimen lebih baik dibandingkan kelas kontrol, pembelajaran dengan pendekatan keterampilan proses sains dalam model discovery terlaksana dengan baik, dan siswa memberikan respons baik selama pembelajaran berlangsung.

Hasil penelitian ini sejalan dengan penelitian terdahulu oleh Ali Gunai Balim (2009) dengan judul 'The Effects Discovery Learning on Students' Success and Inquiry Learning Skills" Hasilpenelitian

menunjukkanbahwa adaperbedaan yang signifikan dalammendukungdarikelompok eksperimendibanding kelompok kontrolmengenairata-rataprestasi akademik, skorretensibelajar, danpersepsiinkuiriskorketerampila $\mathrm{n}$, baik padatingkatkognitif dan afektif. Penelitian oleh Wouter Van Joligen (1999) dengan judul" Cognitive tools for discovery learning" Menyatakan bahwa terdapat pengaruh Model pembelajaran discovery Learning terhadap hasil belajar dan koknitif siswa.

Kelebihan dari model pembelajaran Discovery Learning ini Membantu siswa untuk memperbaiki dan meningkatkan keterampilan-keterampilan dan proses-proses kognitif, Pengetahuan yang diperoleh melalui metode ini sangat pribadi dan ampuh karena menguatkan ingatan, Menimbulkan rasa senang pada siswa, karena tumbuhnya rasa menyelidiki dan berhasil, Metode ini memungkinkan siswa berkembang dengan cepat dan sesuai dengan kecepatannya sendiri, Kemungkinan siswa belajar dengan memanfaatkan berbagai jenis sumber belajar.

Model pembelajaran

Discovery Learning juga memiliki kelemahan diantara nya yaitu : Metode ini menimbulkan asumsi 
bahwa ada kesiapan pikiran untuk belajar. Bagi siswa yang kurang pandai, akan mengalami kesulitan abstrak atau berfikir atau mengungkapkan hubungan antara konsepkonsep, yang tertulis atau lisan, sehingga pada gilirannya akan menimbulkan frustasi, Metode ini tidak efisien untuk mengajar jumlah siswa yang banyak, karena membutuhkan waktu yang lama untuk membantu mereka menemukan teori atau pemecahan masalah lainnya.

Apabila langkah-langkah model pembelajaran Discovery Learning dapat dilakukan seefektif mungkin dan kendala-kendala di atas dapat diatasi maka model pembelajaranDiscovery Learning dapat dijadikan salah satu model pembelajaran yang dapat meningkatkan hasil belajar fisika siswa.

\section{KESIMPULAN}

Setelah

melakukan

penelitian, perhitungan data, dan pengujian hipotesis, maka diperoleh beberapa kesimpulan bahwa : (1) Rata-rata hasil belajar siswa pada materi pokok suhu dan kalor menggunakan Model Pembelajaran Discovery Learning sebesar 75,83 (sedang) dengan kriteria tuntas, dimana $80 \%$ siswa yang tuntas dan $20 \%$ siswa yang tidak tuntas. (2) Rata-rata hasil belajar siswa pada materi pokok suhu dan kalor dengan menggunakan model pembelajaran konvensional adalah sebesar 70,3 (rendah) dengan criteria tidak tunta, dimana $36 \%$ siswa yang tuntas dan 64\% siswa yang tidak tuntas. (3) Hasil belajar siswa pada materi pokok suhu dan kalor yang diberi pembelajaran model pembelajaranDiscovery
Learning lebih baik dari pada model pembelajaran konvensional.

\section{SARAN}

Berdasarkan hasil dan kesimpulan penelitian, maka peneliti mempunyai beberapa saran :(1) Bagi guru fisika hendaknya lebih memahami model pembelajaran Discovery Learning sebagai salah satu upaya untuk menambah kreativitas dan semangat belajar siswa, serta meningkatkan hasil belajar siswa. (2) Dapat menambah wawasan Bagi mahasiswa yang ingin meneliti model pembelajaran Discovery Learning dan pada saat penelitian hendaknya memperhatikan waktu yang tersedia agar pembelajarannya lebih efektif. (3) Bagi para pembaca apabila ingin melakukan penelitian tentang model pembelajara Discovery Learning ini, sebaiknya dilakukan dengan cara melibatkan siswa untuk lebih berfikir kritis terhadap masalah yang diajukan, jadi dalam hal ini bukan hanya guru saja yang memegang peranan tetapi siswa juga dituntut untuk lebih aktif dan kreatif, pada saat praktikum sebaiknya dilakukan dengan baik yaitu dengan memfariasikan prosedur percobaan untuk memperoleh hasil yang maksimal.

\section{DAFTAR PUSTAKA}

Arends, R.I., (2008), Learning to Teach, Belajar untuk Mengajar, Penerbit Pustaka Belajar, Yogyakarta.

Balım, A., G. (2009). The Effects of Discovery Learning on Students' Success and Inquiry Learning Skills. Egitim ArastirmalariEurasian Journal of 
EducationalResearch, 35, 120.

Eggen, Paul, Don Kauchak, (2012), Strategie and Models for Teachers, Diterjemahkan oleh Satrio Wahono, Permata Puri Media, Jakarta.

Kementrian Pendidikan dan

Kebudayaan., (2013),

Gambaran Struktur Matrei Pelatihan Guru

Implementasi Kurikulum

2013, Badan Pengembangan

Sumber Daya Manusia,

Medan.

Lestari, Rini Puji, Suliyanah, (2014), Penerapan

Pendekatan Keterampilan

Proses Sains Dalam Model

Pembelajaran Discovery

Pada Materi Suhu dan Kalor

Terhadap Hasil Belajar

Siswa di MAN 1 Sukomoro,

Jurnal Inovasi Pendidikan

Fisika (JIPF).

Joolingen, Wouter van., (1999),

Cognitive tools for discovery

learning, International

Journal of Artificial

Intelligence in Education, 10, 385-397.

Sudjana, (2005), Metoda Statistik, Penerbit Tarsito, Bandung. 